\title{
Testul Bruckner la 4 metri: Un instrument important în screening-ul ambliopiei la copiii cu dizabilități intelectuale
}

\author{
Iulia-Andrada Nemeș-Drăgan, Ana-Maria Drăgan, Marius Bembea
}

Facultatea de Medicină şi Farmacie, Universitatea din Oradea, România

\begin{abstract}
REZUMAT
Introducere. Screening-ul ambliopiei la copiii cu nevoi speciale trebuie să fie realizat cu teste rapide și obiective, cum este testul Bruckner.

Ipoteza propusă verificării a fost aceea că testul Bruckner la 4 metri, pentru copiii cu dizabilități, ar putea fi cel puțin la fel de util sau chiar superior celui la 1 metru.

Scopul studiului a fost să determine sensibilitatea și specificitatea reflexului Bruckner efectuat la 4 metri comparativ cu cel la 1 metru, pentru detecția ametropiilor și a strabismului la copiii cu dizabilități intelectuale.

Material $\square$ i metodă. Au fost luați în studiu un număr de 34 de copii cu dizabilitate intelectuală. 4 studenți au efectuat testul Bruckner la 1 metru și la 4 metri, apoi expertul oftalmolog a efectuat examinarea oftalmologică completă. Compararea statistică a rezultatelor s-a efectuat folosind testele Fischer și Chi pătrat.

Rezultate. Sensibilitatea testului la 1 metru a fost între 0 şi $50 \%$, iar la $4 \mathrm{~m}$ a fost de $55,6-72 \%(p<0,05)$. Specificitatea testului la 1 metru a fost de $85,7-100 \%$, iar la $4 \mathrm{~m}$ a fost de $81,3-93,8 \%(p<0,05)$.

Concluzii. Extinderea de la 1 metru la 4 metri a distanței de examinare dintre observator și pacient în testul Bruckner crește acuratețea detecției ametropiilor.
\end{abstract}

Cuvinte cheie: ambliopie, copii cu necesități speciale, test Bruckner

\section{INTRODUCERE}

Screening-ul ametropiilor sau al altor patologii care pot produce ambliopie, precum strabismul sau cataracta, este un act medical important atunci când se examinează un copil.

Pentru pacienții cu dizabilităţi intelectuale care nu vorbesc sau la care nu poți să examinezi abilitatea de recunoaștere, este nevoie de teste rapide și ușoare [1]. Acești pacienți cu nevoi speciale sunt o provocare pentru examinator şi necesită metode de testare adecvate, cu examinări de scurtă durată şi un mediu special. Detecția rapidă și corecția patologiei oculare pot ajuta la îmbunătățirea dezvoltării și creșterii acestor pacienți.

Testul Bruckner (sau testul reflexului roșu) este o metodă obiectivă indispensabilă de detecție și diagnostic al viciilor de refracție (miopie, hipermetropie, astigmatism miopic sau hipermetropic), al strabismului și ambliopiei.

Este un instrument util pentru pacienții cu nevoi speciale pentru că necesită doar o minimă colaborare din partea pacientului [2].
Distanța tradițională de care examinatorul are nevoie este de 1 metru sau o lungime de braț. Testul se bazează pe iluminarea simultană a ambilor ochi cu oftalmoscopul și compararea simetriei culorii și luminozității. În mod fiziologic, reflexele roşii trebuie să fie simetrice la ambii ochi [3].

Caracteristicile cromatice și luminozitatea reflexului roșu depind de intensitatea sursei luminoase, calitatea mediilor transparente, gradul de pigmentație a polului posterior și statusul refractiv al pacientului.

Creșterea distanței de examinare cauzează o întunecare a reflexului roșu în cazul unei ametropii, în contrast cu testul clasic, unde reflexul este mai luminos. Motivul pentru care distanța joacă un rol important în testul Bruckner la 4 metri este unul optic: traseul razelor luminoase este unul divergent atât în hipermetropiile mari, acolo unde acomodația nu mai își joacă rolul, cât și în miopie. Razele luminoase care ajung la pupila examinatorului devin gradual mai întunecate și reflexul roșu mai redus [4].

$\mathrm{Cu}$ cât gradul anizometropiei este mai mare, $\mathrm{cu}$ atât reflexul de la ochiul mai ametrop este mai diminuat. Testul Bruckner la 4 metri poate fi util şi pentru 
a evalua o subcorecție sau supracorecție a prescripţiei pacientului.

\section{IPOTEZA DE LUCRU}

Testul Bruckner la 4 metri ar putea fi la fel de util sau chiar superior celui la 1 metru pentru copiii cu dizabilități.

Scopul studiului a fost să determine sensibilitatea și specificitatea reflexului Bruckner efectuat la 4 metri comparativ cu cel la 1 metru, pentru detecția ametropiilor și a strabismului la copiii cu dizabilități intelectuale. Patru studenți de anul IV de la Facultatea de Medicină au jucat rolul observatorilor orbi, fară acces la informațiile clinice ale pacienților, pentru a demonstra utilitatea testului în mâna unui pediatru sau a unui medic generalist.

\section{MATERIAL ŞI METODĂ}

A fost realizat un studiu prospectiv pe 34 de pacienți cu dizabilitați intelectuale, aflați în observația medicală a Departamentului de Genetică al Spitalului Clinic Municipal „Dr. Gavril Curteanu“ din Oradea. Perioada în care a fost efectuat studiul a fost din martie 2018 până în martie 2019. Studiul a fost aprobat de către Consiliul Etic al spitalului. Pentru fiecare pacient luat în studiu s-a cerut și s-a obținut consimțământul informat al părinților.

Pacienții selectați aveau vârste cuprinse între 1 şi 8 ani. Criteriile de includere în studiu au fost pacienți cu sindroame genetice asociate cu dizabilitate intelectuală (IQ sub 70).

Fiind demonstrat că unii copii, cu vârsta cuprinsă între 2 și 8 luni, au o întunecare fiziologică a reflexului luminos [5], au fost excluși din studiu pacienții de 8 luni sau mai mici.

Înainte de începerea studiului, toți cei patru studenți au fost instruiți, într-un stagiu de 2 ore, despre cum să realizeze și să recunoască un reflex Bruckner negativ sau pozitiv folosind lentile sferice și cilindrice de plus sau minus pentru a simula o ametropie [6].

Pentru început, pacienții au fost examinați de expert (oftalmopediatru), iar apoi de cei 4 studenți. Pe tot parcursul examinărilor, a existat o persoană care a notat timpul necesar examinărilor. Testul a fost realizat într-o cameră cu luminozitate scăzută utilizând un oftalmoscop direct (Beta 200, Heine, Germania). Acest instrument a fost prezentat studenților, care au primit instrucțiuni despre cum să îl țină şi cum să privească prin apertura acestuia. Pupilele pacienților nu au fost dilatate. În funcție de vârsta copilului, acesta a fost așezat fie pe scaun separat, fie la unul dintre părinți, în brațe, la o distanță de aproximativ 1 metru de examinator. După aceea, distanța a fost crescută la 4 metri. În cazurile în care complianța a fost foarte scăzută, atenția copilului a fost atrasă cu desene de pe un telefon inteligent sau cu jucării foarte luminoase şi zgomotoase, cu grijă ca luminozitatea obiectului să nu interfereze cu razele luminoase ale oftalmoscopului (Fig. 1). După ce observatorul a câștigat atenția pacientului, pupilele acestuia au fost iluminate simultan. Studentul a trebuit să decidă dacă există (test pozitiv) sau nu există (test negativ) o asimetrie între cele două pupile.

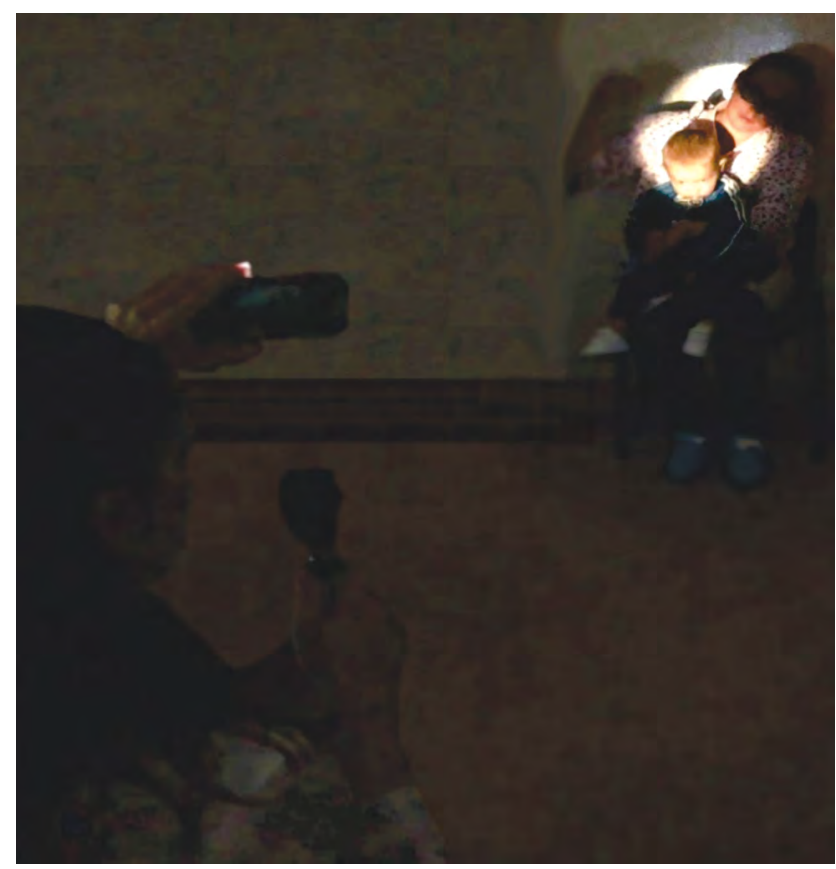

FIGURA 1. Testul Bruckner la 4 metri realizat de un student

După efectuarea testului, toți pacienții au avut parte de o examinare oftalmologică completă, care a inclus examenul fundului de ochi şi cover testul, urmat de o autorefractometrie înainte şi după cicloplegie (Tomey RC-800 Auto Ref/K) sau retinoscopie, în funcție de complianța pacientului.

Cicloplegia a fost realizată folosind instilații de tropicamidă $10 \%$ de 3 ori, la interval de 10 minute. Refracția măsurată după cicloplegie a fost considerată gold standard. Pentru a facilita analiza statistică, viciile de refracţie au fost exprimate în echivalent sferic. Testul Fischer și testul Chi pătrat au fost folosite pentru a verifica dacă există o legatură sau dependenţă între rezultatele expertului şi ale studenților.

\section{REZULTATE}

Am examinat 34 de pacienți,17 de sex masculin și 17 de sex feminin. Toți pacienții aveau o boală geneti- 
că cu dizabilitate intelectuală și majoritatea erau necomplianți pentru vârsta lor. Marea majoritate a pacientilor (28/34) aveau sindrom Down, 4 aveau neurofibromatoză de tip 1,1 pacient avea diagnosticul de craniosinostoză și 1 avea sindrom Crouzon. Vârsta medie a pacienților a fost de 4,26 de ani (vârsta cea mai mică a fost de 1 an, iar cea mai mare de 8 ani).

Cover testul a fost negativ la 24 din pacienți și pozitiv la 10 pacienți, aceștia din urmă prezentând un strabism manifest cu unghi mare.Un număr de 21 de pacienți aveau anizometropie, cu o diferență mai mare de 0,5 dioptrii după refracția cu cicloplegie (exprimată în echivalent sferic). La 1 metru, toți studenții au reușit să detecteze corect majoritatea pacienților fară boală oculară (între $85,7 \%$ și $100 \%$ ) dar au eșuat în identificarea anizometropiei sau a deviației (identificare corectă între $0 \%$ și 50\%).(Tabelul 1).

Sensibilitatea testului în detecția deviațiilor sau a unui viciu de refractie unilateral la 4 metri, realizat de oricare student, a fost mai bună comparativ cu testul la 1 metru. Rata de identificare corectă a fost între 55,6\% și 72,2\% (Tabelul 2).

TABELUL 1. Sensibilitatea şi specificitatea Bruckner testului la 1 metru

\begin{tabular}{|c|c|c|c|c|c|c|c|}
\hline \multicolumn{4}{|c|}{ Bruckner test 1m } & \multirow{2}{*}{ Total } & $\begin{array}{c}\text { Sensibilitate interval } \\
\text { de încredere 95\%) }\end{array}$ & $\begin{array}{l}\text { Valoare predictivă pozitivă (in- } \\
\text { terval de încredere } 95 \% \text { ) }\end{array}$ & \multirow[b]{2}{*}{ Cohen's k (p-value) } \\
\hline & & $\begin{array}{l}\text { Cu boală } \\
\text { oculară }\end{array}$ & $\begin{array}{l}\text { fără boală } \\
\text { oculară }\end{array}$ & & $\begin{array}{l}\text { Specificitate (interval } \\
\text { de încredere 95\%) }\end{array}$ & $\begin{array}{l}\text { Valoare predictivă negativă (coe- } \\
\text { ficient de încredere 95\%) }\end{array}$ & \\
\hline \multirow{2}{*}{ Student1 - $1 \mathrm{~m}$} & Pozitiv & 1 & 4 & 5 & $\begin{array}{c}\mathrm{Se}=16.7 \% \\
(0,9 \%-53,9 \%)\end{array}$ & $\begin{array}{c}P P V=20 \% \\
(11 \%-64,7 \%)\end{array}$ & \multirow{2}{*}{$K=0.004(p=0.881)$} \\
\hline & Negativ & 5 & 24 & 29 & $\begin{array}{c}S p=85,7 \% \\
(82,3 \%-93,7 \%)\end{array}$ & $\begin{array}{c}\mathrm{NPV}=82,8 \% \\
(79,5 \%-90,5 \%)\end{array}$ & \\
\hline \multirow{2}{*}{ Student2 - $1 \mathrm{~m}$} & Pozitiv & 0 & 1 & 1 & $\begin{array}{c}\mathrm{Se}=0 \% \\
(0 \%-15,7 \%)\end{array}$ & $\begin{array}{c}P P V=0 \% \\
(0 \%-94,5 \%)\end{array}$ & \multirow{2}{*}{$k=-0,005(p=0,638)$} \\
\hline & Negativ & 6 & 27 & 33 & $\begin{array}{c}S p=96.4 \% \\
(96.4 \%-99.8 \%)\end{array}$ & $\begin{array}{c}N P V=81,8 \% \\
(81,8 \%-84,7 \%)\end{array}$ & \\
\hline \multirow{2}{*}{ Student3 - $1 \mathrm{~m}$} & Pozitiv & 3 & 0 & 3 & $\begin{array}{c}\mathrm{Se}=50 \% \\
(16,8 \%-50 \%)\end{array}$ & $\begin{array}{c}P P V=100 \% \\
(33,7 \%-100 \%)\end{array}$ & \multirow{2}{*}{$\kappa=0,074\left(p<0,001^{*}\right)$} \\
\hline & Negativ & 3 & 28 & 31 & $\begin{array}{c}S p=100 \% \\
(92,9 \%-100 \%)\end{array}$ & $\begin{array}{c}\mathrm{NPV}=90,3 \% \\
(83,9 \%-90,3 \%)\end{array}$ & \\
\hline \multirow{2}{*}{$\begin{array}{c}\text { Student } 4 \text { - } 1 \\
\mathrm{~m}\end{array}$} & Pozitiv & 1 & 0 & 1 & $\begin{array}{c}\mathrm{Se}=16.7 \% \\
(0,9 \%-16,7 \%)\end{array}$ & $\begin{array}{c}P P V=100 \% \\
(5,5 \%-100 \%)\end{array}$ & \multirow{2}{*}{$K=0,024\left(p=0,028^{*}\right)$} \\
\hline & Negativ & 5 & 28 & 33 & $\begin{array}{c}S p=100 \% \\
(96,6 \%-100 \%)\end{array}$ & $\begin{array}{l}N P V=84,8 \% \\
(82 \%-84,8 \%)\end{array}$ & \\
\hline \multicolumn{2}{|l|}{ Total } & 6 & 28 & 34 & & \multicolumn{2}{|c|}{ * valoarea $p$ este semnificativă, $p<0,05$} \\
\hline
\end{tabular}

TABELUL 2. Sensibilitatea şi specificitatea testului Bruckner la 4 metri

\begin{tabular}{|c|c|c|c|c|c|c|c|}
\hline \multicolumn{4}{|c|}{ Bruckner test $4 \mathrm{~m}$} & \multirow[t]{2}{*}{ Total } & \multirow{2}{*}{$\begin{array}{l}\text { Sensibilitate (interval de } \\
\text { încredere 95\%) } \\
\text { Specificitate (interval de } \\
\text { încredere 95\%) }\end{array}$} & \multirow{2}{*}{$\begin{array}{l}\text { Valoare predictivă pozitivă } \\
\text { (interval de incredere } 95 \% \text { ) } \\
\text { Valoare predictivă negativă } \\
\text { (interval de încredere } 95 \% \text { ) }\end{array}$} & \multirow[t]{2}{*}{ Cohen's k (p-value) } \\
\hline & & $\begin{array}{l}\text { Cu boală } \\
\text { oculara }\end{array}$ & $\begin{array}{c}\text { Fără boală } \\
\text { oculară }\end{array}$ & & & & \\
\hline \multirow{2}{*}{ Student1 - $4 \mathrm{~m}$} & Pozitiv & 13 & 2 & 15 & $\begin{array}{c}\mathrm{Se}=72,2 \% \\
(54,2 \%-81,2 \%)\end{array}$ & $\begin{array}{c}P P V=86,7 \% \\
(65 \%-97,5 \%)\end{array}$ & \multirow{2}{*}{$\begin{array}{c}\kappa=0,194 \\
\left(p<0,001^{*}\right)\end{array}$} \\
\hline & Negativ & 5 & 14 & 19 & $\begin{array}{c}S p=87,5 \% \\
(67,2 \%-97,6 \%)\end{array}$ & $\begin{array}{c}N P V=73,7 \% \\
(56,6 \%-82,2 \%)\end{array}$ & \\
\hline \multirow{2}{*}{ Student2 - $4 \mathrm{~m}$} & Pozitiv & 11 & 1 & 12 & $\begin{array}{c}\mathrm{Se}=61,1 \% \\
(43,7 \%-66,4 \%)\end{array}$ & $\begin{array}{c}P P V=91,7 \% \\
(65,5 \%-99,6 \%)\end{array}$ & \multirow{2}{*}{$\begin{array}{c}\kappa=0,168 \\
\left(p=0,001^{*}\right)\end{array}$} \\
\hline & Negativ & 7 & 15 & 22 & $\begin{array}{c}S p=93,8 \% \\
(74,1 \%-99,7 \%)\end{array}$ & $\begin{array}{c}N P V=68,2 \% \\
(53,9 \%-72,5 \%)\end{array}$ & \\
\hline \multirow{2}{*}{ Student3- $4 \mathrm{~m}$} & Pozitiv & 10 & 3 & 13 & $\begin{array}{c}\mathrm{Se}=55,6 \% \\
(37,4 \%-67,3 \%)\end{array}$ & $\begin{array}{c}P P V=76,9 \% \\
(51,7 \%-93,3 \%)\end{array}$ & \multirow{2}{*}{$\begin{array}{c}k=0,115 \\
\left(p=0,028^{*}\right)\end{array}$} \\
\hline & Negativ & 8 & 13 & 21 & $\begin{array}{c}S p=81,3 \% \\
(60,8 \%-94,5 \%)\end{array}$ & $\begin{array}{l}N P V=61,9 \% \\
(46,3 \%-72 \%)\end{array}$ & \\
\hline \multirow{2}{*}{ Sudent4 - 4 m } & Pozitiv & 12 & 1 & 13 & $\begin{array}{c}\mathrm{Se}=66,7 \% \\
(49,2 \%-71.9 \%)\end{array}$ & $\begin{array}{c}P P V=92,3 \% \\
(68,1 \%-99,6 \%)\end{array}$ & \multirow{2}{*}{$\begin{array}{c}K=0,189 \\
\left(p<0,001^{*}\right)\end{array}$} \\
\hline & Negativ & 6 & 15 & 21 & $\begin{array}{c}S p=93,8 \% \\
(74,1 \%-99,7 \%)\end{array}$ & $\begin{array}{c}N P V=71,4 \% \\
(56,4 \%-75,9 \%)\end{array}$ & \\
\hline \multicolumn{2}{|l|}{ Total } & 18 & 16 & 34 & & \multicolumn{2}{|c|}{ * valoarea $p$ este semnificativă, $p<0,05$} \\
\hline
\end{tabular}


Expertul a avut un timp de reacție semnificativ mai scurt în diagnosticare decât toți cei 4 studenți, atât la 1 metru cât și la 4 metri (testul Mann Whitney U: $\mathrm{p}<0,0125$, cu corecția Bonferroni).

$\mathrm{Nu}$ au existat diferențe semnificative între studenți în ceea ce privește utilizarea testului Bruckner la 1 metru (testul Mann Whitney U: $p<0,0125$, cu corecția Bonferroni), în contrast cu testul realizat la 4 metri, unde au existat diferențe semnificative între timpul de reacție al studenților (testul Kruskal Wallis: $\mathrm{p}=0,434$ $>0,05)$.

Dacă ne îndreptăm atenția doar pe pacienții cu cover test pozitiv, putem observa că studenții care au efectuat examinarea la $1 \mathrm{~m}$ au avut dificultăti în identificarea corectă a pacienților pozitivi comparativ cu examinarea expertului, rata de identificare corectă a bolii a fost între $0 \%(0 / 6)$ până la $50 \%(3 / 6)$. La 4 metri, s-a observat o creștere a ratei de detecție a bolii de la $12,5 \%(1 / 8)$ la $87,5 \%(7 / 8)$.

\section{DISCUȚII}

Rezultatele studiului nostru au arătat că testul Bruckner clasic realizat la 1 metru are o specificitate excelentă (între $87,5 \%$ și $100 \%$ ) și valori predictive negative bune (între $81,8 \%$ şi $91,3 \%$ ) pentru detecția anizometropiilor mari și a strabismului la copii cu dizabilități intelectuale chiar și atunci când sunt efectuate de un nonoftalmolog [6-9].

Atunci când se crește distanța de examinare la 4 metri, sensibilitatea se îmbunătățește semnificativ (de la $16,7 \%$ la $72,2 \%$ ) [6,8]. Strabismul a fost, de asemenea, detectat mai precis la 4 metri comparativ cu 1 metru.

Studiul efectuat de La Mattina K şi colaboratorii a determinat validitatea testului Bruckner pentru anizometropii, demonstrând că acesta poate să fie un instrument rapid și ieftin pentru medicii pediatri dacă aceștia au parte de o pregătire adecvată și este, de asemenea, un test precis pentru oftalmopediatri [10].

Kothari și colaboratorii au comparat screening-ul cu testul Bruckner la $1 \mathrm{~m}$ cu alte metode convenționale de screening în școlile din India, unde testul a avut o sensibilitate excelentă ( $88 \%)$ și valori predictive ne- gative bune (99\%) [11]. Motivul pentru care acest studiu a avut rezultate mai bune decât al nostru se datorează, cel mai probabil, faptului că a fost realizat la copii de școală primară fără dizabilități intelectuale [12].

Jalis M și colaboratorii au demonstrat utilitatea și rapiditatea testului Bruckner la 1 metru pentru a detecta vicii de refracție sferice și asferice semnificative la copii, menţionând că creșterea distanței poate să crească acuratețea testului [13].

Sensibilitatea studiului efectuat în UK de Muen W și colaboratorii luată per total la 1 metru a fost similară ca valori cu cea din studiul nostru $(14,3 \%)$. Ei au concluzionat că, chiar dacă în UK testul reflexului roșu este popular și folosit de majoritatea medicilor de familie, este nevoie de mai multe teste pentru o sensibilitate mai mare [14].

Amitava şi colaboratorii au încercat să simplifice şi să reducă costurile testului Bruckner utilizând retinoscopia și obținând rezultate similare testului clasic cu o acuratețe mai mare de $90 \%$ [15].

$\mathrm{O}$ altă modalitate de screening rapid şi eficient a fost elaborată de Bani S și colaboratorii prin utilizarea unei camere digitale pentru detecția anizometropiei și a strabismului, prin analiza reflexului Bruckner, oferind o alternativă utilă pentru screening-ul ambliopiei în țările în curs de dezvoltare, cu o acuratețe similară cu cea din studiul lui Amitava $[15,16]$.

Studiile conduse de Graf M și Jain și colaboratorii au relevat o concordanță clinică excelentă între oftalmologi și nonoftalmologi, atunci când se folosește testul Bruckner îmbunătățit $[6,17]$.

\section{CONCLUZII}

Testul Bruckner poate fi un test adjuvant și rapid, excelent pentru pediatri, ortopticieni și medici generalişti dacă aceștia au o minimă pregătire și expertiză în domeniu. Acuratețea testului pentru detecția ametropiilor sau a strabismului se îmbunătățește dacă se extinde distanţa de examinare. Astfel, acesta poate fi un instrument precis pentru pacienții cu dizabilități intelectuale la care o distanţă prea apropiată de examinator poate reduce complianța.

\section{BIBLIOGRAFIE}

1. Taub M. Comprehensive Examination Procedures. In: Taun M, Bartuccio M, Maino D Visual Diagnosis and Care of the Patient with Special Needs. Wolters Kluwer Health,2012,155-184.

2. Stephen E, Dickson J, Kindley A. Surveillance of vision and ocular disorders in children with Down syndrome. Dev Med Child Neurol. $2007 \mathrm{Jul} ; 49(7): 513-5$.

3. Lambert S, Lyous C.Taylor and Hoyt's Pediatric Ophthalmology and Strabismus. Edinburgh: Elsevier, 2017.

4. Graf M. The Bruckner test revised. In: Lorenz B, Brodsky M. Pediatric Ophtalmology, Neuro-Ophtalmology, Genetics. Springer. Heidelberg, 2010, 113-124.

5. Archer S. Developmental aspects of the Bruckner test. Ophthalmology. 1988 August: 1098-1101.

6. Graf M, Jung A. The Brückner test: Extended distance improves sensitivity for ametropia. Graefes Arch Clin Exp Ophthalmol. 2008 Jan;246(1):135-41. 
7. Roe L, Guyton D. The light that leaks: Brückner and the red reflex. Surv Ophthalmol. 1984 May-Jun;28(6):665-70.

8. Paysse $E$, Williams $G$, Coats $D$ et al. Detection of red reflex asymmetry by pediatric residents using the Brückner reflex versus the MTI photoscreener. Pediatrics. 2001 Oct;108(4):E74.

9. Gole G, Douglas L. Validity of the Bruckner reflex in the detection of amblyopia. Aust N Z J Ophthalmol. 1995 Nov;23(4):281-5.

10. LaMattina K, Vagge A, Nelson L. Can the Red Reflex Test Detect Unequal Refractive Error? J Pediatr. 2019 Aug 1.

11. Kothari M, Kosumbkar S. Ultra-rapid school vision screening in developing nations using the Brückner test. Am Orthopt $J$. 2010;60:82-6.

12. Kothari M. Can the Bruckner test be used as a rapid screening test to detect significant refractive errors in children? Indian J Ophthalmol. 2007 May-Jun;55(3):213-5.

13. Jalis M, Ashfaq M, Imdad A. Use of Bruckner Test for the Detection of
Significant Refractive Errors in Children. Journal of Rawalpindi Medical College (JRMC); 2015;19(3):200-203.

14. Muen W, Hindocha M, Reddy M. The role of education in the promotion of red reflex assessments. JRSM Short Rep. 2010 Oct; 1(5):46.

15. Amitava A, Kewlani D, Khan Z, Razzak A. Assessment of a modification of Brückner's test as a screening modality for anisometropia and strabismus. Oman J Ophthalmol. 2010 Sep;3(3):131-5.

16. Bani S, Amitava A Sharma R, Danish A. Beyond photography: Evaluation of the consumer digital camera to identify strabismus and anisometropia by analyzing the Bruckner's reflex. Indian $J$ Ophthalmol. 2013:61:608-11.

17. Jain P, Kothari M, Gode V. The opportunistic screening of refractive errors in school-going children by pediatrician using enhanced Brückner test. Indian J Ophthalmol. 2016 Oct; 64(10): 733-736.

Conflict of interest: none declared Financial support: none declared 